\title{
Adolescentes na escola: representações sociais sobre violência
}

\author{
Adolescentes e violência
}

\author{
Maria Beatriz Ribolla \\ Geraldo Antonio Fiamenghi Jr.
}

\section{Resumo}

\begin{abstract}
A presente pesquisa é um estudo sobre as representações sociais da violência em três grupos de adolescentes com idade entre 14 e 17 anos, matriculados em três escolas de ensino médio da zona oeste, na cidade de São Paulo. As informações foram obtidas por meio de procedimentos verbais (discussão em grupo) e não-verbais (colagem), com o objetivo de ampliar a compreensão do fenômeno da violência sob o ponto de vista dos adolescentes e analisadas sob a abordagem da teoria da Representação Social de Moscovici. Os resultados mostraram que as representações sociais sobre a violência foram situações associadas às crianças e aos jovens, às cenas explícitas de destruições, crimes, política e esportes. Os adolescentes identificam-se com as cenas, apontando o medo e a insegurança que o fenômeno provoca. Para os adolescentes, a diminuição da violência passa pela cooperação e conscientização.
\end{abstract}

Palavras-chave: Adolescência; Violência; Representação Social.

\section{Adolescents in school: social representation on violence}

\begin{abstract}
This research investigates the social representation of violence in groups of adolescents in São Paulo and it was developed with three groups of $14-$ to 17-year-old high school students, in three schools located in the West side of the city. Data were collected via verbal (group discussion) and non-verbal (collage) procedures, aiming to enlarge the comprehension of violence from the standpoint of adolescents and were analyzed based upon Moscovici's Social Representation theory. Results showed that social representation of violence appeared in situations associated to children, youths, and graphic scenes of destruction, crimes, politics and sports. Adolescents identify themselves with those scenes, expressing the fear and insecurity that the phenomenon elicits. Decrease in violence passes through cooperation and awareness processes on the adolescents' viewpoint.

Keywords: Adolescence; Violence; Social Representation.
\end{abstract}

\section{Adolescentes en la escuela: representaciones sociales sobre violencia}

\section{Resumen}

Esta investigación es un estudio sobre las representaciones sociales de la violencia en tres grupos de adolescentes con edad entre 14 y 17 años, inscriptos en tres escuelas de enseñanza secundaria de la zona oeste, en la ciudad de São Paulo. Las informaciones fueron obtenidas por medio de procedimientos verbales (discusión en grupo) y no verbales (collage), con el objetivo de ampliar la comprensión del fenómeno de la violencia desde el punto de vista de los adolescentes y analizadas sobre la óptica de la Teoría de la Representación Social de Moscovici. Los resultados mostraron que las representaciones sociales sobre la violencia fueron situaciones asociadas a los niños y a los jóvenes, a las escenas explícitas de destrucciones, crímenes, política y deportes. Los adolescentes se identificaron con las escenas, señalando el miedo y la inseguridad que el fenómeno provoca. Para los adolescentes la disminución de la violencia pasa por la cooperación y concienciación.

Palabras clave: adolescencia, violencia, representación social. 


\section{Introdução}

Vivemos, neste princípio de século, uma profunda busca de explicações sobre as diferentes formas de relacionamentos e interações sociais. As questões que podemos observar como possíveis determinantes nos comportamentos dos adolescentes em relação à violência são: a ausência de rituais de passagem, a construção social de comportamentos, que enfatizam e legitimam o efêmero e a satisfação imediata assim como o incentivo velado à formação de condutas individualistas e egocêntricas como formas de sobrevivência. Concomitante a essas questões, os modelos de conduta que o jovem encontra em nossa sociedade são os que demonstram, escancaradamente, a falta de solidariedade, os excessos de violência, a banalização do sexo, a ampla ilegalidade consentida e, conseqüentemente, a falta de limites entre o público e o privado, acentuando os desmandos e a impunidade. Observamos a falta de uma figura que contemple a ordem e a segurança, como fontes de identificação para a construção de um mundo interno menos conflitante.

Outras características marcam este momento contemporâneo e que fazem parte das vivências dos jovens, tais como a nova estética do cotidiano, ligada à construção da linguagem inconstante dos videoclipes, breves, fragmentados, desfocados, curtos, sem início-meio-fim, aliada à visualidade dos videogames cada vez mais realistas e violentos, rápidos e atribuindo poder a quem os comanda, assim como a construção visual e interacional emergente dos sites e padrões computacionais. Com isso, vive-se a possibilidade de muitas janelas abertas, infinitamente inconclusivas e descartáveis, denotando a construção de uma virtualidade entre o sujeito da ação e o que é produzido.

Diante destes novos padrões interacionais, os jovens criam formas específicas de interpretação do cotidiano, que podem ser percebidas na linguagem, nas roupas, nos locais de encontro, nos comportamentos e nas formas de interação social e, muitas vezes, denotam uma característica cada vez mais fragmentada e confusa.

Por todas as questões até então levantadas, vê-se a carência de estudos sobre o modo como o adoles- cente se apropria de sua realidade em relação à violência. Portanto, a presente pesquisa qualitativa tem como objetivo investigar como o imaginário sobre a violência, construído nas interações indivíduo e sociedade, é explicitado tanto de forma verbal, quanto não-verbal pelos jovens, corporificando as representações sociais sobre o fenômeno da violência.

\section{Representação social na psicologia}

O termo Representação Social surgiu no trabalho do psicólogo social francês Serge Moscovici (196I, 1976). As representações sociais são, basicamente, a teoria de senso comum que norteia as explicações, decisões, pensamentos e atitudes das pessoas em seu cotidiano. Estão constituídas por três aspectos interrelacionados e orientam sua configuração, o cognitivo, o afetivo e o social, cujas dimensões demarcam a formação dos conteúdos, através das informações, que são os conhecimentos acerca do objeto; do campo de representações, que é a organização das informações a partir do imaginário e dos fatores ideológicos e das atitudes, que são as avaliações a respeito deste objeto, em questão. A razão pela qual as pessoas constroem representações sociais está diretamente ligada à necessidade de transformarem em familiar, aquilo que ainda não o é, para que possam compreender a realidade e ter um sentido de pertencimento ao grupo.

Para que tal movimento ocorra, Moscovici (1976) observa que se configura conjuntamente com um sistema econômico e político, um sistema de pensamento na sociedade, onde coexistem duas classes distintas, formando um sistema de comunicação e a construção da realidade. A primeira formada pelos universos consensuais, compostos pelas 'teorias' de senso comum e que fundamentam as relações de interação social do cotidiano. A segunda classe constituída pelos universos reificados, fonte do pensamento erudito e das ciências, com todo o rigor objetivo e metodológico, circundado por um espaço restrito. A passagem deste não-familiar para um conhecimento familiar, que constitui a raiz fundamentadora das representações sociais, ocorre pela tensão produzida na busca de uma nova estrutura cognitiva e emocional. Isto se dá através dos movimentos de ancoragem e objetivação, explicados a seguir. $O$ processo de an- 
coragem consiste na incorporação cognitiva de um objeto desconhecido a um sistema de pensamento já existente, ou seja, em categorias mais familiares. Para tanto, é necessário classificar e denominar. Quando não há a classificação de algo nem a identificação em um campo reconhecido, não se pode nomeá-lo. Logo, ele não existe para o sujeito. $A$ objetivação, o outro processo constituinte da formação das representações sociais, é a materialização das idéias já ancoradas; é dar uma forma ao conhecimento que se obteve sobre o objeto social (Moscovici, 1976).

As representações sociais, compreendidas como mediadoras de condutas, carregam, muitas vezes, valores e características do poder hegemônico em sua constituição. Portanto, configuram fortemente seu papel ideológico dentro da estrutura social a que pertencem. Isto pode ser observado na construção social das necessidades e desejos, dos significados, das referências afetivas e cognitivas que dão origem à compreensão dos fenômenos (Spink, 1995). A necessidade do estudo das representações sociais para compreender o fenômeno da violência na adolescência passa a ser um dos primeiros passos para o entendimento do comportamento violento dos nossos jovens.

Bock, Gonçalves e Furtado (200I) apontam para a inexistência da adolescência como uma fase natural do desenvolvimento, pois ela é construída segundo os padrões culturais que marcam um dado momento na história, podendo ser compreendida inserida no contexto que lhe deu origem; assim, as marcas da contemporaneidade determinam os padrões comportamentais existentes nos jovens hoje. A crise de emprego, a violência, a formação de espaços fechados de convivência (shoppings e condomínios) e a ampliação da escolarização, fazem com que as crianças fiquem mais tempo sob a tutela e supervisão dos pais, encaminhando-se para o mercado de trabalho mais tardiamente. Desta forma, seu comportamento adquire características de maior dependência e menor autonomia diante das decisões.

Erikson (1976) ampliou o campo teórico sobre o desenvolvimento, pois não se restringiu somente à infância. Apontou oito estágios durante a vida e cada um corresponde a uma crise normativa e necessária para $\circ$ desenvolvimento psicossocial, interdepen- dente, tanto das crises anteriores, quanto das posteriores. No momento da adolescência, que para Erikson é a última fase da infância, a crise dirige-se à construção da identidade versus confusão de papéis. Ele acredita que este é um período crucial para a formação da identidade. Outros psicanalistas (por exemplo, Aberastury \& Knobel, 1992) também caracterizaram a adolescência como época de transição.

Neste contexto da adolescência constituída como época de transição e passível de influências sociais importantes, aparece o fenômeno da violência como uma situação à qual os adolescentes estão expostos e com a qual devem lidar.

Pichon-Rivière e Quiroga (1998) salientam um dos fatores psicossociais da constituição do comportamento violento, explicando que "a violência pode ser definida como uma reação coletiva provocada pelo acúmulo de frustrações de indivíduos que, num momento dado, por se identificarem num mesmo conflito adquirem uma pertença" (p.70). Tanto a violência quanto a agressão, estão vinculadas a algum dano, seja ele material, corporal, emocional ou ético. Logo, estão inseridas no contexto das relações sociais. Dentro deste pressuposto, a interação entre as pessoas está fortemente organizada pela interiorização das normas e o autocontrole, estruturados no desenvolvimento da personalidade.

Martuccelli (1999) salienta a idéia, acrescentando que "a sociedade repousa sobre a partilha de valores, que se tornam normas, transformadas por sua vez em personalidade (...) ○ ator violento é sempre alguém que não foi corretamente socializado" (p. 169-170). Se por um lado, existe a idéia de que a pessoa deve ter um autocontrole interiorizado, reprimindo a energia pulsional para ser considerada socializada e então não-violenta, por outro, vê-se que o controle ocorre a partir do externo, pelo 'olhar do outro'. Nesta instabilidade das realidades, o conflito pode ser o pólo gerador da violência. Forma-se, então, o grande vazio das e nas relações, a falta de sentido e significado, a incerteza e a abstinência de papéis, talvez a mola mestra da violência. Isto está intrinsecamente ligado ao que Arendt (200I) analisa como o domínio de Ninguém, isto é: 
“... quanto maior é a burocratização da vida pública, maior será a atração pela violência, pois, (...) é uma forma de governo na qual todas as pessoas estão privadas da liberdade política, do poder de agir, pois o domínio de Ninguém não é um nãodomínio e onde todos são igualmente impotentes, temos uma tirania sem tirano (p. 58-59).

Há uma distinção entre os termos violência, agressividade e agressão, segundo Osório (1999). A agressividade é a propulsão para a ação, necessária para nos impulsionarmos em nossos propósitos, tanto nos construtivos quanto nos destrutivos. Já, o termo agressão possui o caráter negativo e destrutivo da agressividade. A violência estaria situada no extremo da conduta agressiva que possua fins destrutivos. Portanto, há um aspecto mais patológico nas questões que envolvem a violência. A constituição da violência também passa por outros fatores como o discurso produzido pela mídia, orientando um sentido e um significado. Estes instrumentos de comunicação de massa, especialmente a televisão, o rádio, os jornais e as revistas, têm como objetivo apresentar a visão ampliada e direcionada dos fenômenos que não conseguimos enxergar. Assim, são os mediadores daquilo que não conseguimos ver, ou do que não se deixa ver, daí o forte caráter ideológico.

Outra questão relevante dentro do denso processo de constituição da violência são as relações com a construção da alteridade. Segundo Lalande (1999), a alteridade é "característica do que é outro. Opõe-se à identidade" (p.47). Portanto, ela é a capacidade de ser o 'outro' de alguém. Viver a alteridade é também a possibilidade de viver o conflito, a diferença, a estranheza, a contrariedade e a ignorância. A violência se amplia quando se desconhece este outro ou ainda, quando se pretende submetê-lo ou excluí-lo, pois não se reconhece nele um semelhante, não the conferimos os mesmos atributos de humanidade que encontramos em nós. Neste sentido, chega-se à questão da ética e da justiça, pois as duas são formas de relações e, somente com o outro podemos experimentar sermos justos e éticos.

Diante de todas estas questões, quando se atribui ao outro a dimensão do nada ou do vazio, quan- do ele evoca em nós o desconhecido, o não familiar, ele passa a não existir e, por estas razões onipotentes, muitas comunidades foram destruídas, muitos perdem seus direitos, outros tantos são violados e usados. Nestes caminhos encontra-se a violência pela falta do outro introjetado, pela impossibilidade de pensar o homem a partir das relações e da constituição da alteridade, pois ele faz parte daquilo que reconheço em mim. Logo, podese supor que, a partir do momento em que o outro é tido como alguém necessário ao meu modo de agir e de pensar, desperta em mim o desejo de não eliminá-lo, de não violá-lo, mas sim construílo. Pois, descobrindo sua humanidade, revejo a minha e compreendo o que sou.

Diante do exposto, este trabalho propõe-se a estudar as representações sociais sobre a violência em grupos de adolescentes, através da utilização de colagem e discussões em grupos.

\section{Método}

\section{Participantes}

Participaram da pesquisa adolescentes entre 14 e 17 anos, estudantes do ensino médio de duas escolas da rede particular e uma escola da rede estadual, todas localizadas na zona Oeste de São Paulo. Em cada escola, a forma de seleção dos participantes foi diferente, obedecendo às características específicas de cada instituição e suas formas de organização.

$\mathrm{Na}$ Escola I (ESCI), particular, participaram 9 adolescentes (5 meninos e 4 meninas), nos dois encontros. Na Escola 2 (ESC2), pública, participaram 8 adolescentes no $1^{\circ}$ encontro ( 3 meninos e 5 meninas) e no $2^{\circ}$ encontro, 4 adolescentes ( $I$ menino e 3 meninas). Na Escola 3 (ESC3), particular, participaram do $I^{\circ}$ encontro II adolescentes $(6$ meninos e 5 meninas) e, no $2^{\circ}$ encontro, 5 adolescentes ( $I$ menino e 4 meninas).

Logo, o número total de participantes foi, no primeiro encontro (seleção das revistas), de 14 meninos e 14 meninas e, no segundo encontro (colagem e discussão), de 7 meninos e II meninas. 


\section{Materiais}

I) Seleção das revistas: elaboração de uma lista de revistas preferidas pelos adolescentes como fonte de informações para as projeções e escolha de cenas e imagens significativas sobre violência e não-violência.

- materiais para colagem: cartolina, tesoura, cola.

- gravador: uso para gravação da discussão sobre as imagens selecionadas.

2) técnica não-verbal: produção de imagens sobre violência e não-violência, através da colagem do material retirado das revistas selecionadas anteriormente pelo grupo;

3) gravação da discussão sobre a questão da violência, realizada durante e após a conclusão das imagens.

\section{Procedimento}

Solicitou-se aos estudantes que elaborassem uma lista de revistas com o objetivo de indicar seus interesses temáticos e visuais.

Em seguida foi realizada uma colagem (técnica nãoverbal de colagem), por meio da seleção de imagens das revistas, recortes das imagens e posterior colagem em folhas de papel cartolina. Por seu caráter projetivo, a intenção foi buscar o aspecto simbólico e as cognições que envolvem o tema da violência para estes grupos de adolescentes. Os adolescentes foram orientados para folhearem as revistas e retirarem delas fotos, palavras, trechos de reportagens, relacionadas com situações de violência e de não-violência. Após a colagem, foi realizada a discussão sobre as imagens produzidas. $O$ falar sobre as construções não-verbais ampliou a possibilidade dos adolescentes se projetarem e trazerem à tona questões significativas sobre a violência

\section{Análise das informações}

Uma análise das características perceptivas do esquema compositivo, das imagens apresentadas pelos participantes foi realizada, pois num momento inicial, tratou-se do dado mais revelador dos movimentos dos grupos. Tais esquemas são destacados pelas formas de ordenação da configuração, resultantes das relações entre forma, cor, espaço e luz. Expressam os 'estados de ser' que, de forma isomórfica, caracterizam os movimentos internos tais como o equilíbrio/desequilíbrio, dinamismo/estaticidade, fragmentação/totalidade, serenidade/agressividade, lírismo/ dramaticidade etc. Estas categorias foram baseadas em Ostrower (1998). Em seguida, houve uma categorização, não construída $a$ priori, mas em função das escolhas temáticas das imagens utilizadas nas colagens. As categorias e subcategorias encontradas nas imagens são descritas a seguir, nos Quadros I e 2. O Quadro I expõe as categorias e subcategorias referentes às cenas de violência e o Quadro 2 expõe as categorias referentes às cenas de não-violência.

\section{Resultados e Discussão}

Os 28 adolescentes, que participaram na seleção das revistas, elegeram 38 revistas para que fossem utilizadas na tarefa de colagem. Foram realizadas II 5 escolhas entre as três escolas, pois cada participante poderia nomear até 10 revistas de sua preferência, sendo que as três mais votadas de cada escola seriam escolhidas para as colagens. No final, comparados os resultados das três escolas, a revista VEJA apareceu em $I^{\circ}$ lugar, nas três escolas, em termos de preferência global, sendo citada por 61,39\% dos alunos pesquisados; a revista Época apareceu em $2^{\circ}$ lugar, sendo citada por $46,07 \%$ dos alunos pesquisados e a revista Capricho apareceu em $3^{\circ}$ lugar, sendo citada por $34,88 \%$ dos alunos pesquisados.

A análise das imagens produzidas revelou que havia mais imagens sobre violência do que sobre nãoviolência nas revistas escolhidas pelos estudantes e, assim, suas produções também refletiram isto. As construções das imagens VIOLÊNCIA e NÃO-VIOLÊNCIA demonstraram a inexistência de um padrão perceptual compositivo único para a representação dos fenômenos. Houve, também, a necessidade dos adolescentes de elaborar uma estrutura compositiva complementar entre as colagens de VIOLÊNCIA e NÃO-VIOLÊNCIA.

Assim, enquanto na ESCI, a VIOLÊNCIA foi caracterizada por meio de partes autônomas e de as- 
Quadro I. Categorias e Subcategorias da Violência

\begin{tabular}{|c|c|c|}
\hline CATEGORIA & SUBCATEGORIA & DESCRIÇÃO \\
\hline \multirow{3}{*}{$\begin{array}{l}\text { CENAS DE } \\
\text { DESTRUIÇÕES } \\
\text { EXPLICITAS }\end{array}$} & 1. Explosões & $\begin{array}{l}\text { Cenas que mostram a destruição, na hora das explosões, } \\
\text { através de bombas ou mísseis, tanto no meio urbano quanto } \\
\text { no campo. }\end{array}$ \\
\hline & $\begin{array}{l}\text { 2. Destroços e } \\
\text { Escombros } \\
\end{array}$ & $\begin{array}{l}\text { Cenas que mostram a destruição após as explosões de } \\
\text { veículos, construções arquitetônicas e bens. }\end{array}$ \\
\hline & $\begin{array}{l}\text { 3. Animais e Meio } \\
\text { Ambiente }\end{array}$ & $\begin{array}{l}\text { Cenas que mostram a destruição do meio ambiente, o } \\
\text { comportamento violento com os animais e o assassinato } \\
\text { destes. }\end{array}$ \\
\hline \multirow{2}{*}{$\begin{array}{l}\text { CENAS DE } \\
\text { VIOLENNCIA NOS } \\
\text { ESPORTES }\end{array}$} & $\begin{array}{l}\text { 1. Caracterização de } \\
\text { Violência Física }\end{array}$ & $\begin{array}{l}\text { Cenas onde aparecem lutas, ações físicas violentas de } \\
\text { jogadores e a violência das torcidas de futebol. }\end{array}$ \\
\hline & $\begin{array}{l}\text { 2. Sugestão de } \\
\text { Violência } \\
\end{array}$ & $\begin{array}{l}\text { Cenas onde não aparecem atos de violência física, mas } \\
\text { sugerem disputas, discórdias e violação dos direitos. }\end{array}$ \\
\hline \multirow{3}{*}{$\begin{array}{l}\text { CENAS DE } \\
\text { VIOLENCIA } \\
\text { ENVOLVENDO } \\
\text { CRIANÇAS/JOVENS }\end{array}$} & $\begin{array}{l}\text { 1. Vitimas de Ações } \\
\text { Fisicas de Destruição }\end{array}$ & $\begin{array}{l}\text { Cenas que mostram crianças e /ou jovens, passando por ações } \\
\text { de violência física ou presenciando-as, como estudantes em } \\
\text { pânico pelas mortes dos colegas, guarda apontando arma para } \\
\text { a criança e criança ensangüentada sendo carregada. }\end{array}$ \\
\hline & $\begin{array}{l}\text { 2. Vitimas de Ações } \\
\text { Sociais }\end{array}$ & $\begin{array}{l}\text { Fome/preconceito/aliciamento sexual: cenas mostrando } \\
\text { crianças e jovens desnutridos e descuidados, em função da } \\
\text { fome, pobreza, guerra, preconceitos raciais e da idade. } \\
\text { Imagens de meninas participantes da prostituição infantil. }\end{array}$ \\
\hline & $\begin{array}{l}\text { 3. Envolvimento com } \\
\text { Drogas }\end{array}$ & $\begin{array}{l}\text { Cenas que mostram as drogas sendo utilizadas pelos } \\
\text { adolescentes. }\end{array}$ \\
\hline \multirow{2}{*}{$\begin{array}{l}\text { CENAS DE } \\
\text { VIOLÊNCIA } \\
\text { CONTRA A } \\
\text { MULHER }\end{array}$} & $\begin{array}{l}\text { 1. Racismo e } \\
\text { Discriminação }\end{array}$ & $\begin{array}{l}\text { Cenas mostrando as mulheres, em suas diferentes culturas } \\
\text { (branca, negra, india) e a subordinação à leis e normas } \\
\text { sociais e religiosas. }\end{array}$ \\
\hline & $\begin{array}{l}\text { 2. Erotização e Culto } \\
\text { ao Físico }\end{array}$ & $\begin{array}{l}\text { Cenas que enfatizam a erotização feminina e o culto ao físico, } \\
\text { através do condicionamento e do uso do corpo como atrativo } \\
\text { social. }\end{array}$ \\
\hline $\begin{array}{l}\text { OBJETOS } \\
\text { ASSOCIADOS À } \\
\text { VIOLÊNCIA }\end{array}$ & & $\begin{array}{l}\text { Imagens que mostram objetos, tanto do uso cotidiano das } \\
\text { pessoas (dinheiro, cigarro) como objetos simbólicos ligados à } \\
\text { violência e criminalidade (armas) e objetos vindos do } \\
\text { imaginário (mão de ferro com garras). }\end{array}$ \\
\hline $\begin{array}{l}\text { CENAS DE } \\
\text { VIOLÊNCIA } \\
\text { RELACIONADAS À } \\
\text { POLÍTICA } \\
\end{array}$ & & $\begin{array}{l}\text { Cenas que mostram imagens de políticos, terroristas, protestos } \\
\text { populares contra o governo e as eleições e a intimidação das } \\
\text { pessoas através de estratégias políticas e militares. }\end{array}$ \\
\hline $\begin{array}{l}\text { CENAS DE } \\
\text { VIOLENCIA } \\
\text { ENVOLVENDO A } \\
\text { FAMÍLIA } \\
\end{array}$ & & $\begin{array}{l}\text { Cenas e frases que dizem respeito às atitudes das pessoas, no } \\
\text { âmbito familiar como a infidelidade e a violência contra os } \\
\text { familiares. }\end{array}$ \\
\hline $\begin{array}{l}\text { CENAS DE } \\
\text { VIOLÊNCIA } \\
\text { ASSOCIADAS A } \\
\text { CRIMES } \\
\end{array}$ & & $\begin{array}{l}\text { Cenas que mostram crimes ligados a assassinatos. Imagens } \\
\text { associadas a crimes como os de traficantes }\end{array}$ \\
\hline $\begin{array}{l}\text { CENAS DE } \\
\text { VIOLENACIA } \\
\text { CULTURAL }\end{array}$ & & $\begin{array}{l}\text { Cenas que mostram situações de violação e extermínio dos } \\
\text { hábitos culturais }\end{array}$ \\
\hline OUTROS & & $\begin{array}{l}\text { Cenas que mostram pessoas com aparência de desânimo, } \\
\text { medo, tristeza e impotência. }\end{array}$ \\
\hline
\end{tabular}


Quadro 2. Categorias de Não-Violência

\begin{tabular}{|c|l|}
\hline CATEGORIA & \multicolumn{1}{|c|}{ DESCRIÇÃo } \\
\hline ESPORTES & $\begin{array}{l}\text { Cenas que mostram pessoas praticando esportes (surf, ciclismo, tênis } \\
\text { de praia, skate), torcedores e jogadores em atitudes não agressivas. }\end{array}$ \\
\hline RELAÇÕES FAMILIARES & $\begin{array}{l}\text { Cenas que apontam situações de convívio entre os membros da } \\
\text { família, pais e filhos. }\end{array}$ \\
\hline $\begin{array}{c}\text { RELACIONAMENTO } \\
\text { AMOROSO }\end{array}$ & Cenas que mostram casais de namorados. \\
\hline $\begin{array}{c}\text { CONVIVÊNCIA EM } \\
\text { GRUPOS/COMUNIDADE }\end{array}$ & $\begin{array}{l}\text { Cenas que mostram pessoas e animais em grupos, caracterizando a } \\
\text { convivência e a amizade. }\end{array}$ \\
\hline ECOLOGIA E NATUREZA & Cenas que apontam locais da natureza que estão preservados. \\
\hline CULTURA & $\begin{array}{l}\text { Cenas que denotam o acesso à cultura, através dos livros e das } \\
\text { manifestações culturais como a música e o teatro. }\end{array}$ \\
\hline AUXÍLIO E CUIDADOS & $\begin{array}{l}\text { Cenas que mostram pessoas em atitudes de atenção e cuidado com as } \\
\text { outras pessoas, os animais, o meio e consigo proprio. }\end{array}$ \\
\hline $\begin{array}{c}\text { SÍMBOLOS/OBJETOS } \\
\text { LIGADOS A NÃO-VIOLÊNCIA }\end{array}$ & $\begin{array}{l}\text { Objetos e símbolos associados às representações de manifestação de } \\
\text { afeto (flores, corações, urso de pelúcia, filhote de cachorro). }\end{array}$ \\
\hline
\end{tabular}

pecto fragmentado, sem núcleos temáticos, maior estaticidade em sua forma de equilíbrio e na disposição espacial de suas partes, a NÃO-VIOLÊNCIA foi apresentada como uma estrutura oposta, com integração intensa entre as partes, maior dinamismo, tentativas de organização de núcleos temáticos, aspecto tridimensional em sua organização espacial, alto grau de emocionalidade, através das cores e formas e uma área central de intenso poder de síntese.

Também, em termos complementares, na ESC2, a VIOLÊNCIA, representada com maior dinamismo, através da circularidade crescente e da tridimensionalidade sem núcleos temáticos com menor fragmentação entre as partes, teve seu contraponto na representação da NÃO-VIOLÊNCIA com poucos elementos visuais, com uma organização estrutural tendendo à simetria lateral, oferecendo uma disposição geométrica entre as partes, a acentuação da estaticidade, maior fragmentação, separação e autonomia entre as partes.

Quando não houve a complementação das polaridades, em termos estruturais (ESC3) nas duas construções, de forma explícita, devido à semelhança compositiva, fez-se necessária a continuação da atividade, no sentido de elaborar a separação visível e concreta da violência e da não-violência. Nesta terceira escola, as três colagens (violência, não-violência e violência $X$ não-violência) enfatizaram o caráter altamente simétrico e estático, assim como a presença de um centro de grande interesse, tensão e força e a fragmentação entre as partes.

Logo, pode-se observar que, quando houve ampliação do espaço da VIOLÊNCIA - suporte maior (ESCI) - as partes ficaram fragmentadas e autônomas, tornando cansativa e mais lenta a observação, como se houvesse a necessidade de tempo e espaço para ocorrer a compreensão de todas as partes e faces da violência. Nesta composição, o percurso visual se perde, frente a tantos estímulos que não estão conectados perceptivamente, só em função do tema; - olhar salta de uma parte à outra, desordenadamente. Já, no espaço menor (ESC2), ela foi configurada de forma mais dinâmica, com uma estrutura em espiral, dando a sensação de tridimensionalidade, ou seja, o espaço foi ampliado em outra dimensão. Para que isso ocorresse, foi necessário estabelecer relações de continuidade entre as partes, maior dinamismo e um 
enquadramento da imagem total, onde pudesse estar segura em um plano e podendo se expandir na profundidade. $O$ olhar percorre a imagem pelas curvas que formam a grande espiral.

Outra solução encontrada (ESC3) para a quantidade de imagens sobre a violência foi a confecção de nova colagem, ou seja, outro espaço. A imagem da VIOLÊNCIA foi estruturada simetricamente, apontando um equilíbrio estático, com uma situação central em destaque. Os eixos verticais e horizontais acentuados dividem a composição em espaços fechados, faixas que se equilibram. $O$ percurso visual está acentuado da esquerda para a direita, mas os olhos se fixam na imagem central, por sua localização, autonomia e significado.

A análise das relações entre as imagens dos três grupos aponta qualidades essenciais para a compreensão das representações sociais de adolescentes sobre violência. Percebe-se, também, que nas imagens relativas à VIOLÊNCIA, os textos são mais presentes. Eles estão em todas as configurações com o objetivo de explicitar e confirmar diretamente os dados mostrados nas cenas.

Não houve diferenças entre o conteúdo exposto nas escolas particulares e na escola pública, indicando que, da perspectiva dos adolescentes, o fenômeno da violência é semelhante, mesmo porque as escolas estão situadas no mesmo entorno geográfico, diminuindo as diferenças sócio-econômicas, que existem obviamente.

Parece que as imagens indicaram informações que necessitam de mais espaço para a elaboração, quer esteja representando a violência em duas dimensões, em três, ou na construção de um novo campo, de uma racionalidade e direcionamento, através do verbal para sustentar uma afetividade que pode estar desordenada ou não compreendida. Há uma relação temporal que se manifesta mais lenta quando a bidimensionalidade e a simetria são mais intensas. Entre as informações existem brechas, buracos, vazios, sem um significado claro: é o espaço para diferenciar, respirar, olhar, compreender, não estabelecer contato, ou ○ quê? Às vezes, há proximidades; outras, sobreposições, que não chegam a esconder a forma, mas apenas tocá-la, numa tentativa sutil de relacionála, para então compreendê-la (Osório, 1999).
É como se os adolescentes dissessem que há um excesso de informações e eles não sabem o que fazer com isto. Concomitantemente, se perguntam como organizá-las, de um jeito expressivo, se ainda não sabem muito bem o significado das coisas, até agora em construção. Do ponto de vista da representação social, parece que os adolescentes ainda não ancoraram as informações, conseqüentemente não conseguem objetivá-las (Moscovici, 1976; Spink, 1995).

O núcleo temático mais representativo da VIOLÊNCIA, para o grupo total de adolescentes, foi obtido pela quantificação categorial das imagens, de acordo com o Quadro I e Quadro 2, diante de um total de 72 imagens utilizadas, as Cenas de violência envolvendo crianças/jovens (23,61\%, nos 3 grupos), Cenas de destruições explícitas (18,05\%, em 2 grupos), Cenas de violência associadas a crimes (15,27\%, nos 3 grupos) e as Cenas de violência relacionadas à política ( $12,5 \%$, nos 3 grupos) foram as mais encontradas. Já, as Cenas de violência nos esportes foram encontradas em apenas um grupo, com 7 imagens, em um total de $9,72 \%$ das imagens utilizadas. Estas categorias compreendem o núcleo temático mais expressivo sobre a violência do grupo pesquisado (Quadro I) e apontam para as representações sociais do fenômeno (Moscovici, 1976): o envolvimento de crianças e jovens, enquanto vítimas de ações sociais e de destruições conjuntamente com as drogas; atos de destruição explícitos; os crimes contra as pessoas envolvendo assassinatos em sua maioria; o envolvimento da política e dos políticos e a falta de credibilidade e, os esportes em seu aspecto destruidor.

Em contraposição à violência, os temas mais citados pelos jovens nas imagens sobre a não-violência, foram inicialmente os esportes, os objetos e símbolos ligados à não-violência, os relacionamentos amorosos e, com a mesma intensidade, as imagens associadas à cultura, à família e à convivência em grupos. As relações de auxílio e cuidados e as questões ecológicas foram as menos citadas (Quadro 2).

$\mathrm{Na}$ perspectiva deste grupo de adolescentes, o que é a violência e seus tipos, foi caracterizado tanto por aspectos físicos quanto morais. Não houve ênfase em uma só questão, mas sim na interação destes fatores por ocorrerem conjuntamente. Dentre as formas de 
violência citadas, foram evidenciadas as ações físicas contra o outro (brigas, assassinatos), as ações de destruição da natureza e do meio ambiente, as manifestações de preconceitos (idade, raça, classe social), a autoviolência, a falta de respeito e de humildade, a violência produzida pelo descaso político, as ações originadas pelo uso de drogas, a violação do corpo, através da prostituição, a violência cultural e as cenas e imagens mostradas pela mídia tanto de sexo quanto de ataques físicos (Martuccelli, 1999).

As explicações sobre o fenômeno passaram por algumas dualidades como a existência da relatividade sobre um ato, podendo ser entendido como violento ou não, dependendo da interpretação de quem observa o fenômeno e sobre a compreensão da natureza do ato violento, como algo instintual, ou não (Moscovici, 1994).

Em oposição à violência, a não-violência foi carregada de aspectos simbólicos, que podem levar à ampliação da compreensão da violência para o grupo. $\mathrm{Na}$ tentativa de explicar aquilo que é oposto à violência, os adolescentes se apropriam de um discurso em que buscam a fraternidade e a ajuda ao outro, o desejo de carinho, atenção e de estar junto, estar com algo ou alguém. Contudo, demonstram, também, um distanciamento destas atitudes, colocando-as sobre o patamar da utopia e da inexistência no cotidiano, isto é, uma dificuldade de perceber e conviver com a alteridade (Lalande, 1999).

Ainda, dentro das perspectivas discutidas pelo grupo sobre as causas da violência, os fatores apontados foram variados, como a falta de instrução da sociedade, o aprendizado familiar da violência, a falta de apoio dos pais e a solidão, a sensação de banalização da violência, a falta de felicidade, o pensamento mais voltado para si mesmo, o excesso de informações sobre violência nas diversas mídias, assim como seu aspecto explosivo e carnavalesco, a violência como uma construção do desejo de cada pessoa, as drogas como instauradoras da violência, as atitudes desonestas dos políticos que diminuem as chances de trabalho para a população. Essa situação, de um vazio de posições e valores definidos instaura o que Arendt (200I) explicita como o ‘domínio de Ninguém'.

Quanto aos lugares e situações de maior violência, os adolescentes apontaram que não há hora e nem lugar para a violência, mas que ela pode ser percebida, com maior evidência, na família, na escola e na televisão (Osório, 1999; Spink, 1995).

Em relação ao gênero, faixa etária e profissões associadas à violência, foi apontada uma igualdade em relação ao homem e à mulher; os menos violentos foram considerados os velhos e as crianças, sendo que a faixa etária dos adolescentes foi tida como a mais violenta, na opinião dos participantes em relação à profissão. Algumas estão mais associadas à vivência com os atos de violência, assim como com a proximidade das drogas, como os policiais, carcereiros, os advogados e os médicos.

No tocante às soluções para os problemas da violência e como combatê-los, foram levantadas algumas propostas como: a ampliação e organização do acesso à educação, a mudança da 'cabeça das crianças' sobre o que é certo ou não, através da educação e do exemplo, a organização de grupos que possam reivindicar melhorias e pressionar os governantes, assim como ajudar as pessoas, o perdão como ponto de partida, e, finalmente, que o início do combate seja o movimento particular de cada um, no sentido de deixar de ser violento. Novamente, observa-se uma tentativa de juntar aspectos do universo consensual, com o reificado (Moscovici, 1976) para que se possa reduzir a tensão provocada pelo desconhecido, e ainda não ancorado pelos adolescentes.

Considerando-se os resultados, pode-se identificar que o adolescente se vê diante dos muitos eventos, aos quais necessita posicionar-se para então compreender o seu cotidiano. No espaço, entre o acesso às informações e a formação do conceito, existe um momento de elaboração cognitivo-afetivo onde estão presentes as paralisações e/ou as ações impulsivas como fatores organizadores do pensamento.

Neste sentido, há um turbilhão de valores, crenças, expectativas sociais e emoções que se misturam à constituição do processo de identificações que ele percorre, na passagem do infantil para o adulto, até que consiga dominar sua identidade, conforme afirma Erikson (1976).

Junto a este turbilhão, a veiculação do fenômeno violência, pelos meios de comunicação de massa, sugere uma acentuação das informações mais agressi- 
vas ou violentas, constatada entre os adolescentes participantes da presente pesquisa, vindo a interferir na percepção dos jovens sobre o que seria algo não violento, confirmando Martucelli (1999), que discute a situação da violência e socialização.

A violência é algo dinâmico, com aspectos sobrepostos e/ou próximos, instigando um movimento confuso, assim como a circularidade e o conflito; ora ela é estática, paralisadora, com aspectos autônomos e fragmentados, que não se consegue integrar, logo não se configura como um todo, mas como vários "todos". O núcleo temático que o grupo configurou em suas representações sociais foram as imagens de violência mostrando situações associadas às crianças e aos jovens, às cenas explícitas de destruições, aos crimes, à política e aos esportes. As representações sociais, portanto, permitem, como afirma Moscovici (1994), que se faça sentido àquilo que não compreendemos, por meio da ancoragem e da objetivação.

Há uma nítida identificação com as cenas, apontando o medo e a insegurança que o fenômeno provoca em suas vidas. Além disso, a representação da violência, que mostra as destruições e os crimes, perfaz o imaginário instigado pela mídia, banalizando-a pelo excesso de informações, assim como o descrédito das ações e das pessoas envolvidas na política (Arendt, 200I).

Quanto aos fatores que levam à violência, vê-se que, em termos de representação social, as causas estão depositadas, em sua grande maioria, no outro. Em relação aos lugares da violência, eles acreditam que não há definições. Mas, admitem que tanto a família, quanto a escola e a televisão são espaços que promovem ações violentas, confirmando as pesquisas realizadas por Njaine e Minayo (2003), em relação à violência na escola e por Koller (1999), sobre a violência doméstica.

Os adolescentes também apontam soluções para - problema da violência, mesmo desacreditando que possa haver a eliminação do fenômeno. Uma delas é a ampliação do acesso à educação, pois crêem que é uma das armas possíveis de mudança social. Outra, que complementa a educação, é a mudança da forma de pensar das crianças, sobre o que é certo e o que não é, acrescentando à educação o exemplo como forma de atuação. Além disso, acreditam que a organização em grupos, em ONGs e partidos políticos podem ampliar as manifestações sociais e as novas propostas de intervenção junto aos órgãos governamentais.

Mas, o que realmente marca e amplia todas as possibilidades apontadas, caracterizando o desejo de estabelecer relações humanas e solidárias (logo, o despertar da alteridade), tão necessárias neste início de século, foi a constatação de que a diminuição da violência passa por um movimento particular de conscientização onde cada um pode mostrar ao outro, através do seu comportamento, como equacionar as diferenças sem violar o espaço alheio e que o perdão é o primeiro passo a ser dado neste longo caminho de resgate da paz.

Os adolescentes mostram ao mundo adulto que: ...não tem jeito de acabar com a violência, mas ela pode diminuir...

...se os políticos melhorarem dá prá consertar alguma coisa...

...não adianta os políticos se as pessoas não querem...

...eu acho que o perdão é o caminho mais correto...porque às vezes você comete uma violência contra uma pessoa tentando revidar...e quando você perdoa alguém que fez mal prá você, você dá um final naquilo que poderia gerar mais violência...

(participantes das ESCI, ESC2 e ESC3)

\section{Referências}

Aberastury, A., \& Knobel, M. (1992). Adolescência normal. Porto Alegre: Artmed.

Arendt, H. (200I). Sobre a violência. Rio de Janeiro: Relume Dumará.

Bock, A. M. B., Gonçalves, M. G. M., \& Furtado, O. (200I). Psicologia sócio-histórica: Uma perspectiva crítica em psicologia. São Paulo: Cortez.

Erikson, E. H. (1976). Infância e sociedade. (2 ${ }^{\mathrm{a}}$ ed.). Rio de Janeiro: Zahar. 
Koller, S. (1999). Violência doméstica: Uma visão ecológica. Em AMENCAR - Associação de Apoio à Criança e ao Adolescente (Org.), Violência doméstica (pp. 32-42). Brasília: UNICEF.

Lalande, A. (1999). Vocabulário técnico e crítico da filosofia. São Paulo: Martins Fontes.

Martuccelli, D. (1999). Reflexões sobre a violência na condição moderna. Revista Tempo Social: Revista de Sociologia da USP, II(I), I57-I75.

Moscovici, S. (I96I). La psychanalyse, son image et son public. Paris: PUF

Moscovici, S. (1976). La psychanalyse, son image et son public. Paris: PUF.

Moscovici, S. (1994). Des represéntation collectives aux représentations sociales: Éléments pour une histoire. Em D. Jodelet (Org.), Les représentations sociales (pp. 62-86). Paris: Presses Universitaries de France.
Njaine, K., \& Minayo, M. C. S (2003). Violência na escola: Identificando pistas para prevenção. Interface - Comunicação, Saúde, Educação, 7(13), I19-134.

Osório, L. C. (1999). Agressividade e violência: o normal e o patológico. Em J. V. T. dos Santos (Org.), Violência em tempo de globalização (pp. 522-542). São Paulo: Hucitec.

Ostrower, F. (1998). A sensibilidade do intelecto: Visões paralelas de espaço e tempo na arte e na ciência. Rio de Janeiro: Campus.

Pichon-Rivière, E., \& Quiroga, A P.(1998). Psicologia da vida cotidiana. São Paulo: Martins Fontes.

Spink, M. J. (Org.). (1995). O conhecimento no cotidiano: As representações sociais na perspectiva da psicologia social. São Paulo: Brasiliense.

Recebido em: 14/02/2006

Revisado em: 05/02/2007

Aprovado em: 12/06/2007

Sobre os autores:

Maria Beatriz Ribolla (mbrib@ig.com.br) é Mestre em Distúrbios do Desenvolvimento (Universidade Presbiteriana Mackenzie), Professora da UNISAL e da FAAP.

Geraldo A. Fiamenghi Jr. (fiamenghi@mackenzie.br) é PhD em Psicologia (Universidade de Edimburgo, Escócia) e Professor do Programa de Pós-Graduação em Distúrbios do Desenvolvimento (CCBS - Universidade Presbiteriana Mackenzie).

Endereço para correspondência:

Prof. Dr. Geraldo A. Fiamenghi Jr.

Universidade Presbiteriana Mackenzie - CCBS

Pós-Graduação em Distúrbios do Desenvolvimento

R. da Consolação, 896, I․ Andar, s. II4.

0I 302-907 Consolação - São Paulo/SP 